\title{
The air-abrasive technique: A re-evaluation of its use in fossil preparation
}

\author{
Mark R. Graham and Lu Allington-Jones
}

\begin{abstract}
This paper outlines the history of air-abrasion (also known as airbrasion) as a paleontological preparation technique and evaluates various powders and their properties. It explores the rationale behind the selection of abrasive powders and presents, for the first time, trench-scatter experiments through Scanning Electron Microscope (SEM) photography and three-dimensional (3-D) profiling. This article also offers general practical advice and details the results of an international survey of practising fossil preparators.
\end{abstract}

Mark R. Graham. The Conservation Centre, Core Research Laboratories, The Natural History Museum, Cromwell Road, London, SW7 5BD UK. m.graham@nhm.ac.uk

Lu Allington-Jones. The Conservation Centre, Core Research Laboratories, The Natural History Museum, Cromwell Road, London, SW7 5BD UK. I.allington-jones@nhm.ac.uk

Keywords: air-abrasive; preparation; fossil; conservation; air abrasion

Submission: 31 August 2017 Acceptance: 2 August 2018

\section{INTRODUCTION}

There are many different techniques available to the fossil preparator, and selection depends on several factors; the taphonomy of the material to be prepared, fossil hardness, chemistry and stability, the properties of the material to be removed, as well as limitations of the available tools within individual laboratories. Acids and other macerators are utilised when matrix and fossil possess disparate chemistry and therefore will dissolve in different chemicals. When chemical preparation is unsuitable or impractical, there is a wide range of mechanical methods utilising various tools; electric engravers, pneumatic pens, rock grinders, dental picks, steel points in a pinchuck, rotary brushes, ultrasonic cavitation, ultrasonic probes, wooden picks and many more. Frequently, when assessing appropriate treatments for individual specimens, a sequence of different mechanical techniques, or a combination of chemical and mechanical approaches, obtains the best result and great care must be taken in selecting the appropriate tools, materials and techniques. Consideration must also be given to subsequent analytical techniques

Graham, Mark R. and Allington-Jones, Lu. 2018. The air-abrasive technique: A re-evaluation of its use in fossil preparation. Palaeontologia Electronica 21.2.2T 1-15. https://doi.org/10.26879/815 palaeo-electronica.org/content/2018/2279-air-abrasive-fossil-preparation 
employed in interpreting the prepared fossil material to avoid potential loss of data (Green, 2001).

Air-abrasion (a stream of powder in pressurised gas) will often succeed where no other technique can, for example pneumatic tools must not be used on unstable (e.g.,fractured) blocks, but air-abrasive techniques do not cause vibration and are considered lower risk (May et al., 1994). Scattered and rebound particles could, however, cause damage to delicate specimens, and it is not a technique to be chosen without due consideration. Moreover, there is a bewildering array of variables, with profuse types of air-abrasive powder materials (differing in hardness, particle size and shape), feed quantity, nozzle size, angle of operation and gas pressure.

While undoubtedly a valuable technique in removing matrix, revealing fine detail and cleaning the surfaces of fossils, air-abrasion can have a det- rimental effect if applied with insufficient controls over the variables described above, with the consequent reduction or even complete loss of surface detail. With the advent of routine SEM and CT scanning in palaeontology, it is increasingly important to minimise unwanted damage caused by mechanical preparation, especially in the case of smaller specimens where excessive abrasion may cause a significant amount of scarring, the effects of which are very obvious during scanning at micro-level (Figure 1).

In order to incorporate into this paper as many abrasive powders, equipment and techniques as are commonly used in palaeontological preparation, an online survey, targeted at international fossil preparators via SurveyMonkey ${ }^{\circledast}$ was undertaken. Invitations to participate in the survey were advertised via social media and online geological and fossil-related websites and forums.

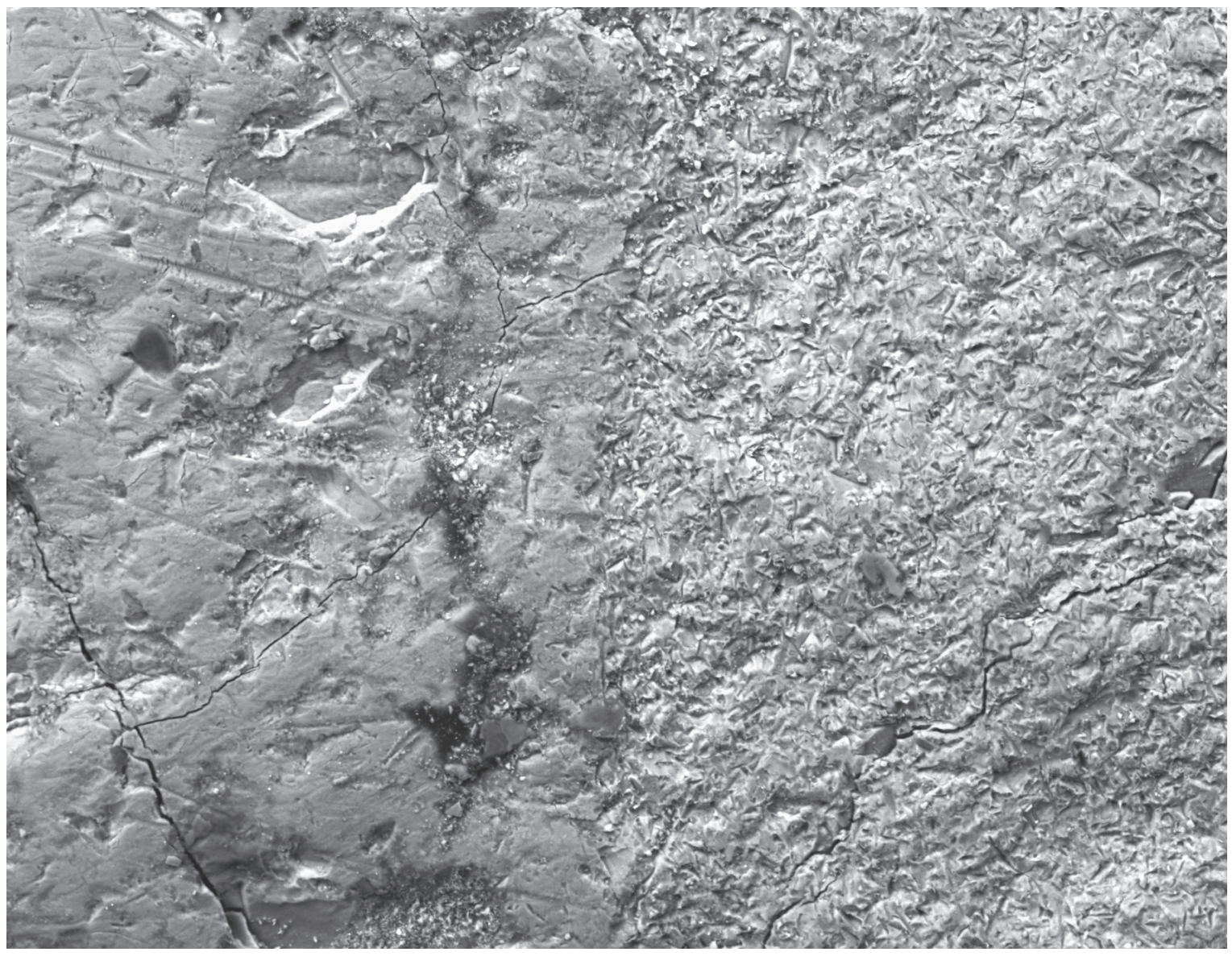

FIGURE 1. An example of damage caused by air-abrasion on a piece of dinosaur rib bone (unregistered float). The untreated bone surface is in the left-hand half of the image, while the right-hand half has been abraded for 5 seconds with $53 \mu \mathrm{m}$ aluminium oxide powder, delivered via a $1 \mathrm{~mm}$ diameter nozzle from $1 \mathrm{~cm}$ distance. The abraded half shows significant pitting and complete loss of the bone surface. (304 x magnification SEM image at 20Pa variable pressure and $12 \mathrm{~mm}$ working distance). 


\section{AN OVERVIEW OF THE HISTORY OF AIR-ABRASIVES}

Air-abrasion was invented in 1871 for industrial applications (Veloz and Chase, 1989) and introduced to dentistry in the 1940s (Swan, 2011). Stucker et al. (1965) present air-abrasive as a new technique for fossil preparation, following Stucker (1961), but the technique had in fact been in use at other institutions for over 70 years (Bernard, 1894; Osborne, 1904). Powders available in the 1960s comprised of aluminium oxide (coarsest grade 50 $\mu \mathrm{m}$ for bulk matrix removal and $27 \mu \mathrm{m}$ for moderately hard matrix), calcium magnesium carbonate for mineral films overlying teeth or bone and sodium bicarbonate for "tissue-thin" bone (Stucker et al., 1965). They also specify 30 psi for extremely delicate work, with a normal working pressure of $100 \mathrm{psi}$, and advise that air-abrasive is more effective on "hard" rather than "elastic" matrices and that matrices with varying hardness should not be prepared using air-abrasive due to the risk of sudden changes in resistance endangering the fossil. Stucker (1961) used compressed carbon dioxide at 30-100 psi through a $46 \mathrm{~mm}$ circular bore tungsten carbide nozzle, or a rectangular nozzle for precision cutting. Stucker (1961) deems the techniques to be "miraculous" but also warns against use on matrices of uneven hardness (sandstones and sandy siltstones) and states that the air-abrasion is "ineffective" on soft matrices. This may be because he had only trialled blocky particles, which will bounce off soft media. Spreng, (1962) utilised only two powders $(27 \mu \mathrm{m}$ aluminium oxide at $80-100 \mathrm{psi}$ for un-weathered rock and calcium magnesium carbonate at 40-50 psi for weathered) and noted that a $1 \mathrm{~mm}$ abrasion diameter results from a 10 $\mathrm{mm}$ working distance, the focus area controlled through varying the working distance. Spreng (1962), recommending the use of working under a binocular microscope protected by a glass-lidded box, notes that the powders could in theory be reused, and comments that "specimens are damaged much less than when cleaned with other tools previously available."

Allman and Lawrence (1972) only mention airabrasive powders within the context of lapping, while Rixon (1976) recommends fine-grained dolomite for chalk fossils, and a combination of acid and air-abrasive, for the removal of matrix that is harder than the fossil. Rixon also mentions sodium bicarbonate as an air-abrasive powder and warns that aluminium oxide can damage the fossil if it rebounds in hollows or the nozzle is held too close. Gunther et al. (1979) adapted hypodermic needles to reduce wear on nozzles and recommended dolomite for fine work. Converse (1984) recognised that, with distance from the nozzle, the particle stream widens and the cut formed has more angular walls. Both recommended $10 \mu \mathrm{m}$ aluminium oxide for fine work, and $50 \mu \mathrm{m}$ aluminium oxide for bulk matrix removal. In 1988, when dolomite powder became difficult to obtain, Hannibal et al. suggested that certain agricultural products could be used, as long as they were sieved and kept dry. Hannibal (1989) lists a wider range of air-abrasive powders, which were available, and states that dolomite is most suitable for preparing shale, limestone or siltstone matrices, and sodium carbonate for removing soft material and for delicate work. They also recommend the practise of $x$-raying specimens to enable anticipation of covered features. May et al. (1994) recommend unspecified coarse powders for bulk matrix removal to within $25 \mathrm{~mm}$ of the specimen and repeat Rixon's advice on powder choice. Wilson (1995) states that the ideal powder will be harder than the matrix and softer than the fossil.

\section{Air-abrasives in Conservation}

Air-abrasives have gained popularity within the field of remedial conservation from the 1960s (although the type of powder, and other variables, are rarely mentioned in published articles, so it is difficult to judge how useful this information is for fossil preparation). Air-abrasion has been used for cleaning stone sculpture (Considine, 2010; Larson and Dinsmor, 1984), corroded steel (Koh et al., 2007), buildings (Larson, 2011), a medieval glass mosaic (Swan, 2011) and even ethnological materials (Gibson, 1969). Air-abrasives have also been used for removing corrosion products from archaeological iron on its own (Blackshaw, 1982) or in conjunction with laser cleaning (Dickman et al., 2005). Veloz and Chase (1989) present a more thorough investigation of air-brasive cleaning of bronze statues, and their findings offer some insights to the fossil preparator in that smaller particles clean porous crusts more effectively than larger particles, and that 3 or more degrees on Moh's scale of hardness should separate the powder and the object (the object being the harder). They also found that the erosion rate of brittle materials increases as the angle of impact nears $90^{\circ}$, but the erosion rate of ductile materials increases with reducing angles.

Harder particles are more aggressive while larger particles will carry more impact, removing matrix faster but also producing a more uneven 
surface. Not only do the commercially available micro-abrasive powders vary in hardness and size, they also vary in shape, and selection can be confusing. The majority of the particles are blocky (aluminium oxide, crushed glass, pumice, sodium bicarbonate) and will supply a cutting action, but they may bounce off a pliable surface. Needle-like sodium bicarbonate crystals are more likely to cut into a ductile matrix. Allington-Jones and Bernucci, (2015) found that sodium bicarbonate used at sufficient duration and pressure for the cleaning of plaster of Paris from sub-fossil bone (40 $\mathrm{Pa}, 7 / 10$ AJM intensity) caused the removal of $13 \mu \mathrm{m}$ of the surface of the specimen. Spherical glass beads react in the opposite manner to sodium bicarbonate, bouncing off hard surfaces and creating sheen through pounding (peening). This compression eventually leads to embrittlement and the formation of deformation chips (Veloz and Chase, 1989). Gibson, (1969) found glass beads to be the least damaging media on extremely pliable surfaces, which yield under the impact of high velocity spherical particles, and could be used to clean leather and strong silk textiles. Although fossil matrices are far less pliable than leather, this demonstrates the importance of choosing the correct particle shape, as well as hardness. Preparators and conservators should be aware, however, that glass bead powders commonly contain broken fragments, which could cause unexpected results (Veloz and Chase, 1989).

\section{Industrial Use of Air-abrasives}

Air-abrasion is a routine process in fossil preparation, and it is enlightening to consider what has been learnt elsewhere in the industrial application of this process. There are many interesting, and sometimes surprising, applications within the industrial sector. For example, metal layers on ceramic piezo devices can be removed with glass beads before firing and with crushed glass after firing, while wheat starch is used by NASA to remove conformal coatings from printed wiring assemblies because it generates little static electricity (Swan, 2011).

Swan (2011) lists some general guidelines that can be of use in fossil preparation:

1) When the diameter of the nozzle doubles, the resulting flow is quadrupled;

2) The air-abrasive stream forms a cone-shape with an included angle of approximately 80 ; 3) Although keeping the nozzle close to the substrate increases accuracy, holding it too close could impede flow as gas expansion is impeded;

4) With greater distance between the nozzle and the substrate, the speed of the air-abrasive slows and the larger the size of abrasive pattern;

5) The nozzle should be held in the direction to be cleaned so that over-spray lies in the correct area;

6) Blasting at an angle allows the air to flow underneath flakes of the unwanted material;

7) Too much air-abrasive to air ratio will prevent the air from expanding and therefore reduce velocity, especially when using small diameter nozzles at low pressure.

Currently there is a wide array of available abrasive powders (Table 1). Comco Inc, for example, supply crushed glass, glass bead, plastic media, pumice, silicon carbide, sodium bicarbonate and walnut shell at set particle sizes and aluminium oxide in different particle sizes. Airbrasive@ (2015) rate different powders according to their suitability within industrial applications

TABLE 1. Hardness, shape and some of the particle sizes available for the most popular air-abrasive powders.

\begin{tabular}{lclc}
\hline Air-abrasive Powder & $\begin{array}{c}\text { Hardness } \\
(\text { Mohs })\end{array}$ & \multicolumn{1}{c}{ Shape } & $\begin{array}{c}\text { Available Particle Size } \\
(\boldsymbol{\mu m})\end{array}$ \\
\hline Aluminium oxide & 9 & Blocky and sharp & $10-150$ \\
Silicon carbide & 9 & Blocky and sharp & $20-50$ \\
Glass beads & 6 & Spherical & $35-100$ \\
Crushed glass & $5-6$ & Blocky and sharp & $50-75$ \\
Pumice & 6 & Blocky and sharp & 75 \\
Dolomite & $3.5-4$ & Blocky & 150 \\
Plastic & $2-4$ & Blocky & $50-200$ \\
Walnut shell & $3-4$ & Blocky & 250 \\
Sodium bicarbonate & $3-4$ & Monoclinic & $50-100$ \\
Wheat starch & 2 & Lenticular and spherical & 100 \\
\hline
\end{tabular}




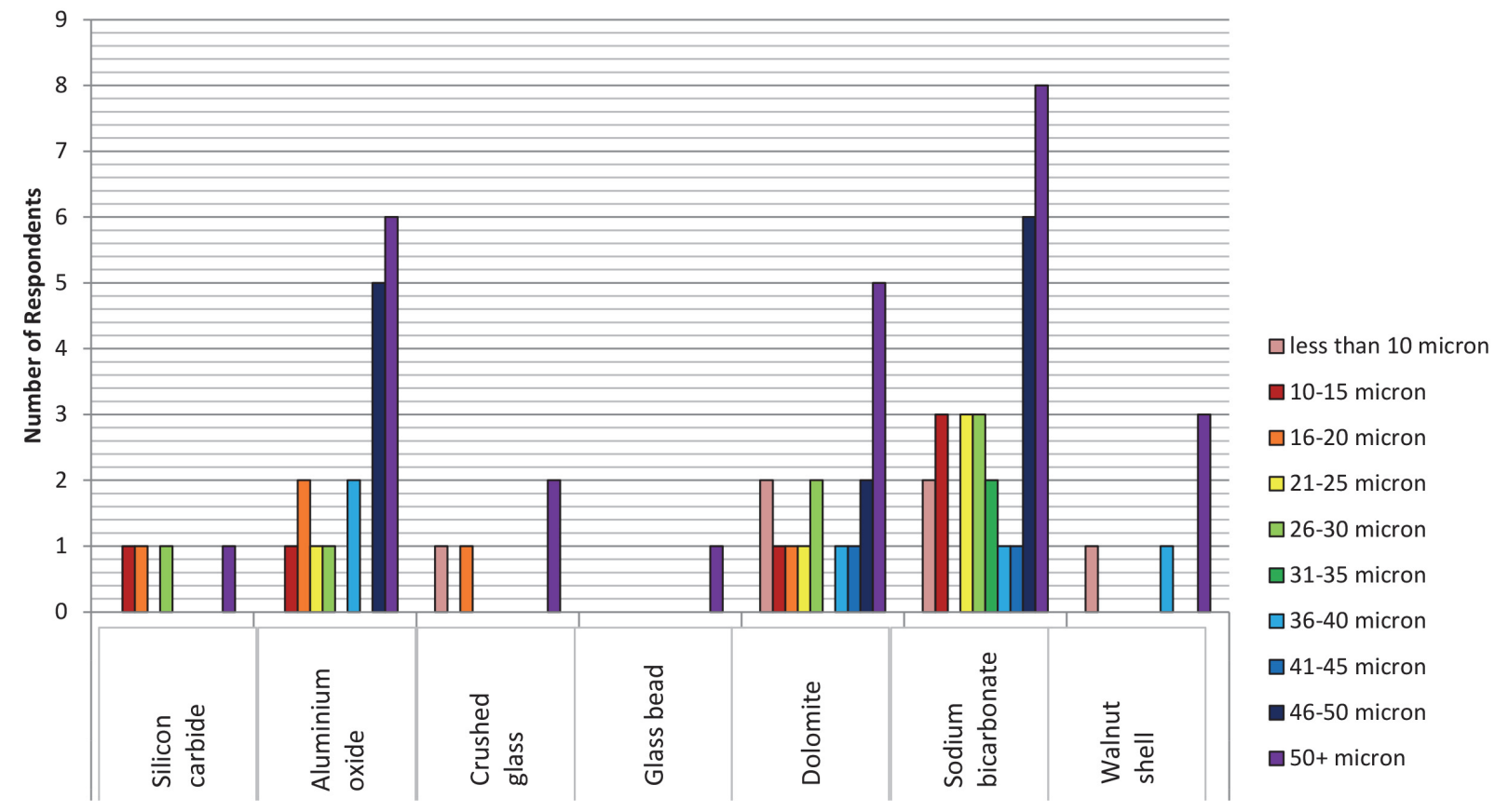

Powder Type

FIGURE 2. Powder type and size used by the respondents of the survey. Respondents also reported use of: Iron 150$200 \mu \mathrm{m}$, garnet, rice flour 100-200 $\mu \mathrm{m}$, potato flour 20-200 $\mu \mathrm{m}$, pumice $50 \mu \mathrm{m}$, Armex composite formula, Tantalum beads and calcium carbonate $150-200 \mu \mathrm{m}$.

for cutting, etching, drilling, peening, abrading, deburring, delicate cleaning, aggressive cleaning and conformal coating removal, and also recommend different sizes of powder for different applications. For example, aluminium oxide $27 \mu \mathrm{m}$ is most suitable for deburring and etching, while the $50 \mu \mathrm{m}$ particle size is preferred for cutting. Glass beads are recommended for peening and removing surface shine (Airbrasive (C), 2017a). Graphs showing the relationship between different parameters when abrading glass can be found at Airbrasive (C) (2017b). These show, unsurprisingly, that with increased air pressure and with increase in particle size, an increase in material removal occurs, but some of the other relationships are more interesting. For example powder flow and nozzle distance from substrate both produce an arch-shaped data plot [also observed by Converse (1984)]. Thus it is clear that a wide range of experimentation may be required by the fossil preparator before commencing work.

\section{INTERNATIONAL ELECTRONIC SURVEY}

Professional, commercial and amateur fossil preparators were invited to participate in an on-line survey 'Air abrasive use in fossil preparation'. The questionnaire was hosted on SurveyMonkey ${ }^{\circledR}$ and publicised via email contacts, preparator/conservator interest groups and social media. A total of 84 individual respondents took part.

Of the respondents, almost half were from the United States of America, 30\% from the UK and $10 \%$ from Canada. Just over half were non-commercial museum or institutional professionals. The largest groups had been working in preparation for either less than three years or over ten years. The results were varied but certain trends emerged: to remove bulk matrix adjacent to the fossil the majority of preparators used larger nozzle sizes, higher air pressure and a greater powder flow than for work directly on the surface of the fossil. Foot feed was more popular and considered to offer more control than continuous feed. The most popular powders were aluminium oxide, sodium bicarbonate and dolomite (Figure 2). The use of personal protective equipment (lab coat/apron, eye protection, face mask and ear protection) was split evenly (Figure 3). Only 60\% used magnification when undertaking air-abrasion (Table 2), and less than $60 \%$ would consider changing nozzle shape and diameter according to specimen or matrix type. The full results can be viewed as an electronic supplement in the Appendix. 


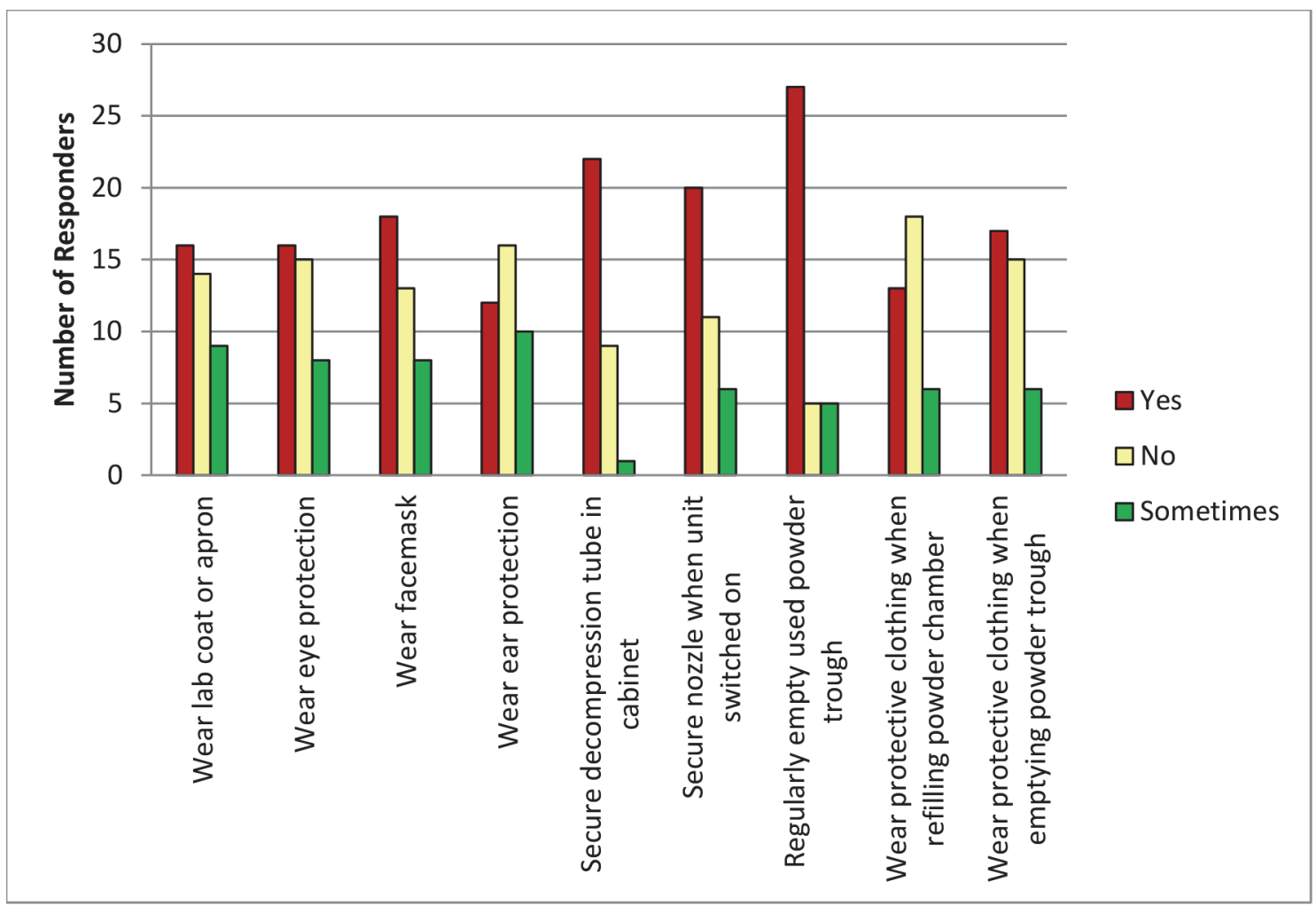

FIGURE 3. Health and safety precaution responses from the survey.

\section{RECYCLING POWDERS}

There are several concerns regarding the reuse of spent air-abrasive powders; contamination, humidification, changes in particle size and shape. Where attempts to recycle powder are concerned, impurities mean inconsistency of performance. Contamination with matrix particles introduces a completely uncontrolled aspect to airabrasion, while certain powders, such as Dolomite, may absorb atmospheric moisture and cause clogging of equipment. Rounding of particles means they are more likely to pound a surface than strip it, causing not only compaction but also an increase of rebound, risking the specimen. Breakage of spherical particles will create sharp edges and

TABLE 2. Elements incorporated into blast cabinets. * Of the remainder $(66.7 \%)$ who responded negatively, $58.7 \%$ said they wore protective gloves.

\begin{tabular}{lc}
\hline \multicolumn{1}{c}{ Element/Equipment } & \% Responders \\
\hline Dust Extraction/venting & 98.3 \\
Integral lighting & 84.5 \\
Magnifying lens & 60 \\
Integral gauntlets & $33.3^{*}$ \\
\hline
\end{tabular}

cause an undesired cutting action. Iron powder is the only air-abrasive medium that has been found suitable for recycling, but it should not be separated using a magnet (which will impart an electrostatic charge) and the used powder must be stored in labelled containers, only to be re-used on the same rock type (Mike Eklund, personal commun., 2017).

Within this study two contrasting powders were examined using SEM: glass beads, to investigate breakage and shape change from spherical to sharp and blocky, and sodium bicarbonate to investigate rounding of the monoclinic crystal form. Samples of fresh and singly-used powders were mounted on a stage using carbon tape and imaged using a LEO 1455VP SEM. SEM images of the two trialled powders are presented in Figures 4 and 5 . The glass beads showed contamination from fragments of matrix, plus the breakage of some particles. The sodium bicarbonate exhibited contamination plus a slight rounding of the crystal forms and a reduction in average particle size. Although these changes were minor, they would be amplified with repeated use. 

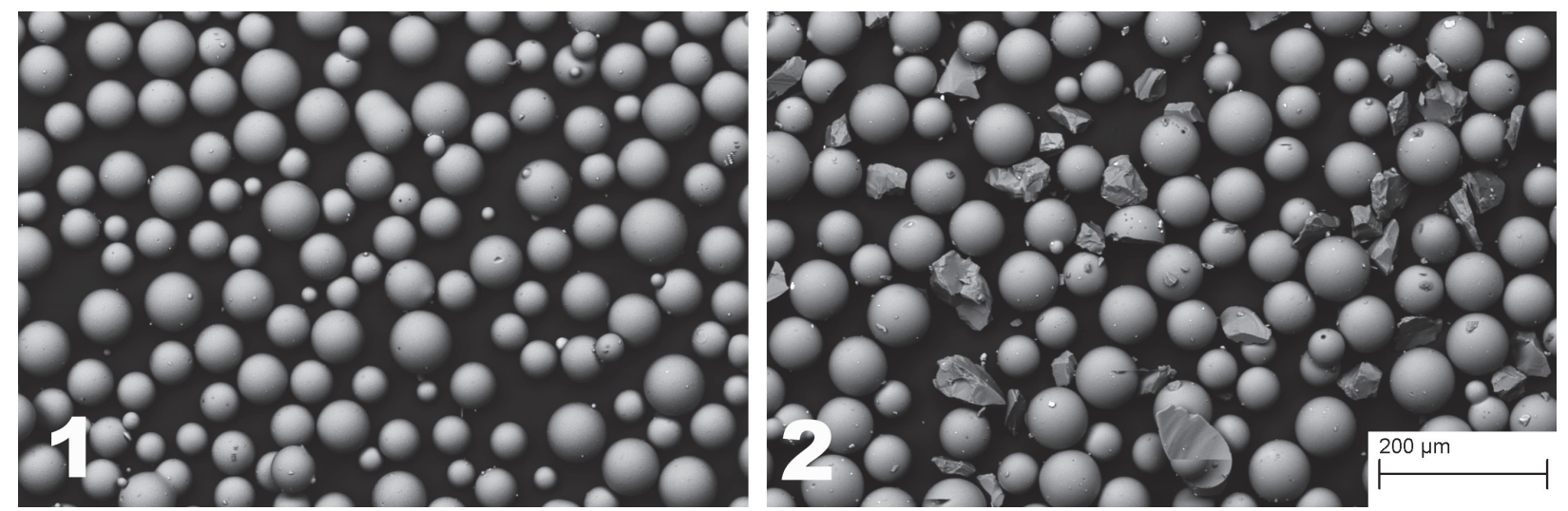

FIGURE 4. Twinned SEM images of glass bead powder. Left (4.1): before use. Right (4.2): after single use.

\section{TRENCH-SCATTER TESTS}

\section{Method}

Trench-scatter tests were established to investigate the blast radius of a representative selection of readily-available air-abrasive powders. A small clamp scaffold was set up to hold the $0.75 \mathrm{~mm}$ diameter air-abrasive nozzle steady and to control angle of incidence, height from matrix surface and distance from focal point. The air-abrasive unit used was Texas Airsonics model HP-1.

Samples of medium-hard limestone (Solnhofen) were prepared from the same block with a coat of Paraloid B72 in acetone and copper powder to enable a visual assessment of particle scatter under SEM. This created an unexpected added advantage in that a halo was created by powder spray so that the maximum width and length affected by abrasion could be observed (Figure 6). The nozzle was set at $30 \mathrm{~mm}$ from the surface of the matrix block in all but one case. Angle of incidence was varied between 90 and 15 degrees from horizontal. The duration of blasting was set at 5 seconds for all tests and air pressure was maintained at 60 psi (4 bar) with a powder feed of 5 AJM. Trench depth was quantified through profile
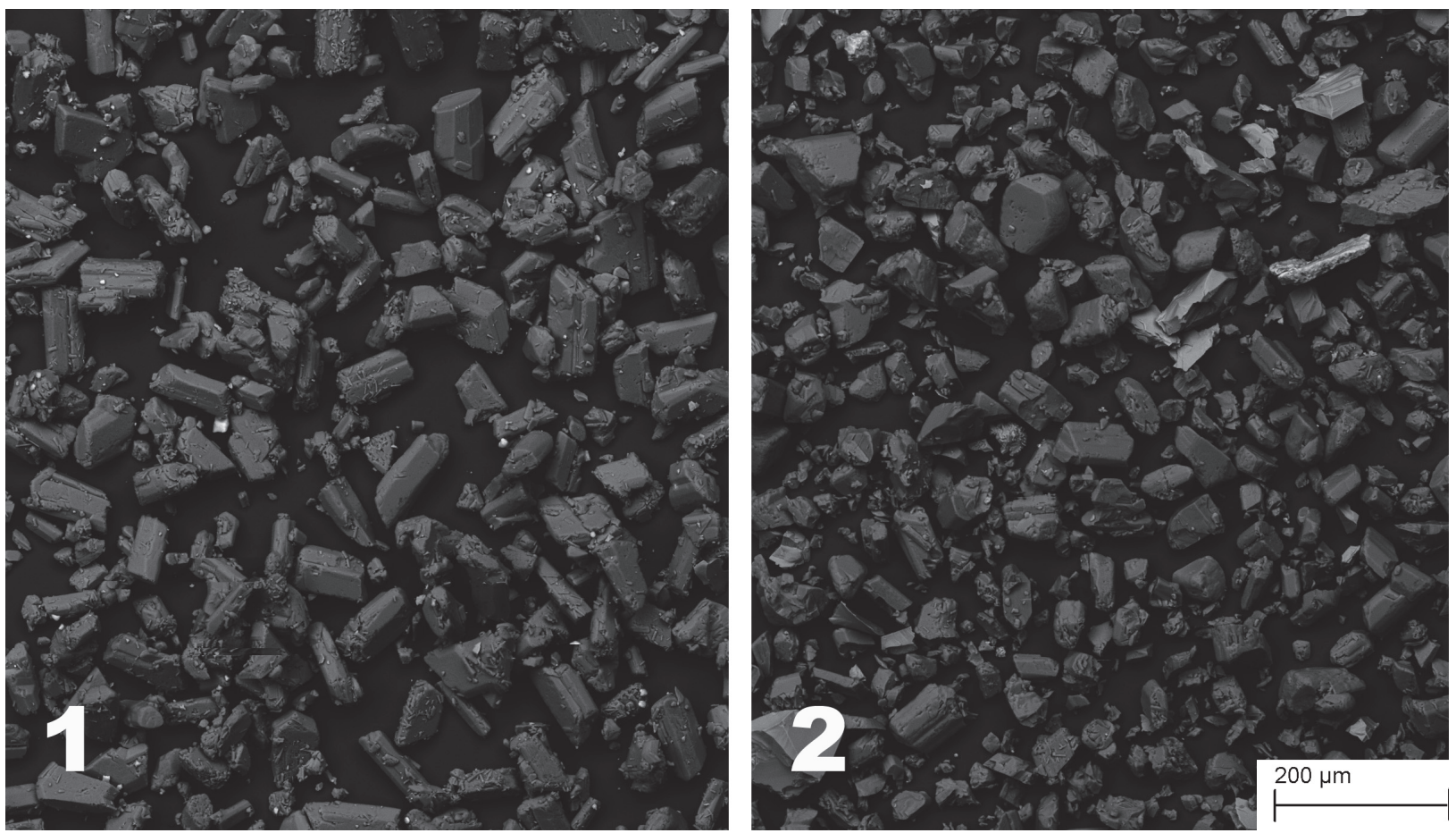

FIGURE 5. Twinned SEM images of sodium bicarbonate powder. Left (5.1): before use. Right (5.2): after single use. 


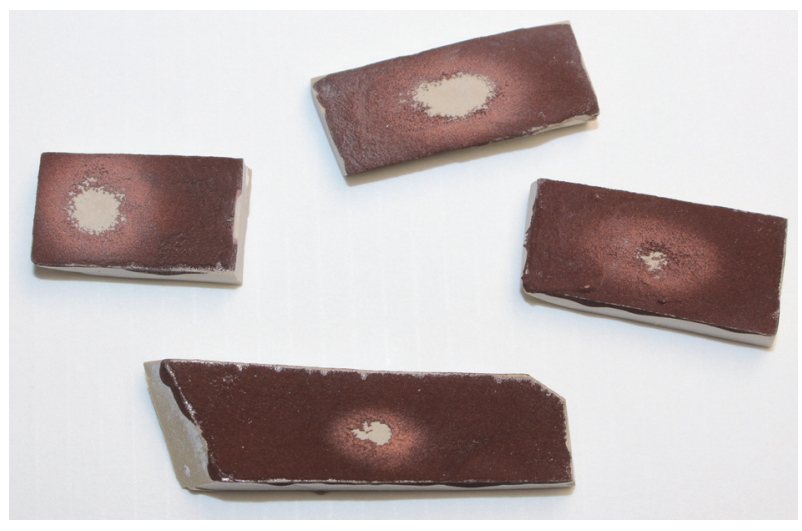

FIGURE 6. Four polished limestone samples, painted with Paraloid B72 and copper powder, each showing an abraded central area with a polished copper halo surrounding it, which would not normally be visible with the naked eye.

construction using a LEO 1455VP SEM, taking images at 0 and 6 degrees tilt and constructing a 3D surface using MeX 5.1 software. Halo width and length was measured using a Draper Expert electronic calliper.

Particle size was investigated by comparing 10 and $50 \mu \mathrm{m}$ aluminium oxide, which was chosen as it is a widely used powder. Particle shape was investigated by comparing crushed (blocky and sharp) and bead (spherical) glass (both at $50 \mu \mathrm{m}$ and 6 Mohs hardness), and also by comparing plastic (blocky 2-4 Mohs) and sodium bicarbonate (monoclinic 3-4 Mohs). Plastic was selected for trials instead of walnut shells out of consideration for a colleague's nut allergy. Hardness can be com- pared between aluminium oxide (9 Mohs) and crushed glass (6 Mohs), both at $50 \mu \mathrm{m}$ particle size with a blocky and sharp shape. The difference between powders of the same stated attributes was investigated by contrasting pumice to crushed glass (both $50 \mu \mathrm{m}, 6$ Mohs) and aluminium oxide to silicon carbide (both $50 \mu \mathrm{m}, 9$ Mohs). Nozzle angle and working distance were only varied when testing aluminium oxide.

\section{Results}

The variables set out in Table 3 and Figures 713 include powder type and particle size, delivery angle and working distance. The dimensions of the trenches created (e.g., scatter width 5.54-11.73 $\mathrm{mm}$, scatter length 9.63-26.23 mm, trench depth $<10-500 \mu \mathrm{m}$ ) are shown. The $50 \mu \mathrm{m}$ plastic powder only removed the resin paint and slightly dimpled the matrix below.

\section{Discussion}

The trench scatter experiments reinforced most of the logical guesses that can be made about air-abrasive use:

1) As the angle between the nozzle and substrate increases towards perpendicular, forward scatter decreases;

2) Trench depth increases with a reduced working distance between nozzle and substrate;

3) The softest powders created the shallowest trenches and the hardest powders created the deepest trenches, with the exception of aluminium oxide (a phenomenon which has also been

TABLE 3. The results of the trench scatter tests.

\begin{tabular}{lccccc}
\hline \multicolumn{1}{c}{ Powder } & Angle & $\begin{array}{c}\text { Working } \\
\text { distance }(\mathbf{m m})\end{array}$ & $\begin{array}{c}\text { Scatter width } \\
(\mathbf{m m})\end{array}$ & $\begin{array}{c}\text { Scatter length } \\
(\mathbf{m m})\end{array}$ & $\begin{array}{c}\text { Trench depth } \\
(\boldsymbol{\mu m})\end{array}$ \\
\hline Aluminium oxide $(10 \mu \mathrm{m})$ & 30 & 30 & 8.58 & 16.42 & 450 \\
Aluminium oxide $(50 \mu \mathrm{m})$ & 30 & 30 & 7.9 & 16.94 & 50 \\
Aluminium oxide $(50 \mu \mathrm{m})$ & 30 & 15 & 7.57 & 12 & 375 \\
Aluminium oxide $(50 \mu \mathrm{m})$ & 15 & 30 & 8.39 & 26.23 & $<10$ \\
Aluminium oxide $(50 \mu \mathrm{m})$ & 45 & 30 & 11.23 & 16.1 & 100 \\
Aluminium oxide $(50 \mu \mathrm{m})$ & 90 & 30 & 11.73 & 11.79 & 500 \\
Crushed glass $(50 \mu \mathrm{m})$ & 30 & 30 & 6.85 & 13.37 & 375 \\
Crushed glass $(50 \mu \mathrm{m})$ & 45 & 30 & 6.96 & 13.32 & 430 \\
Glass bead $(50 \mu \mathrm{m})$ & 30 & 30 & 8.73 & 14.93 & 350 \\
Pumice $(50 \mu \mathrm{m})$ & 30 & 30 & 8.31 & 14.01 & 75 \\
Silicon carbide $(50 \mu \mathrm{m})$ & 30 & 30 & 11.31 & 17.76 & 425 \\
Sodium bicarbonate $(50 \mu \mathrm{m})$ & 30 & 30 & 6.06 & 11.06 & 30 \\
Plastic $(50 \mu \mathrm{m})$ & 30 & 30 & 5.54 & 9.63 & 20 \\
\hline
\end{tabular}




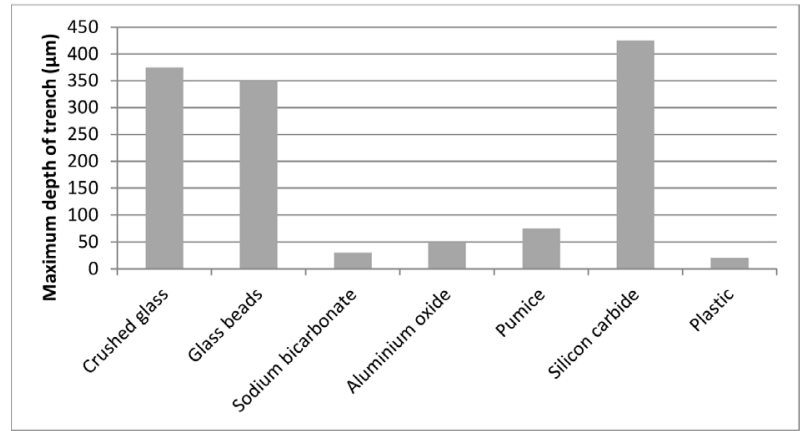

FIGURE 7. Comparison between powder types at $50 \mu \mathrm{m}$ particle size, $30^{\circ}$ angle and $30 \mathrm{~mm}$ working distance between nozzle and substrate.

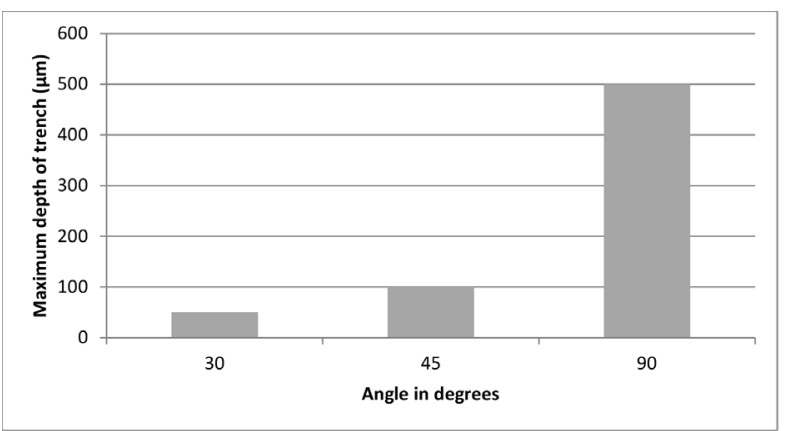

FIGURE 8. Comparison between nozzle angles in relation to the substrate using $50 \mu \mathrm{m}$ Aluminium oxide powder.

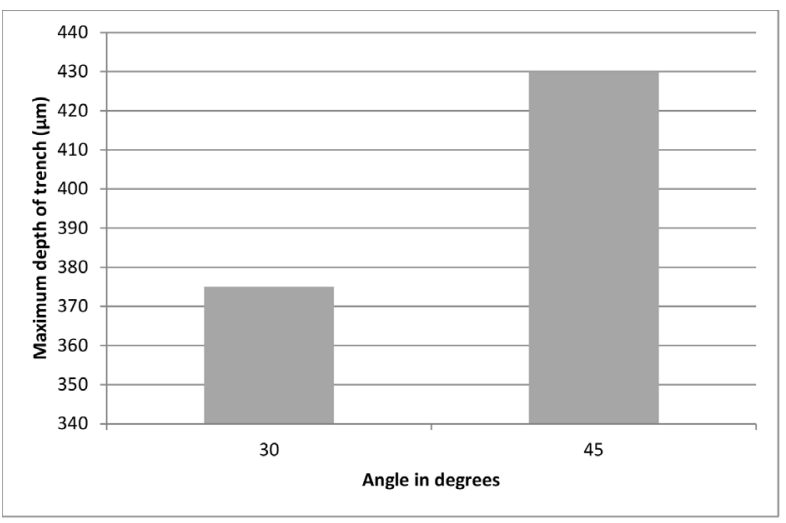

FIGURE 9. Comparison between nozzle angles in relation to the substrate using $50 \mu \mathrm{m}$ crushed glass.

observed at the NHM through anecdotal evidence);

4) The harder powders create larger halos around abraded trenches than softer powders;

5) A smaller halo scatter was created at a shorter working distance; and

6) Preparators must remain wary of the unseen spread of powder.

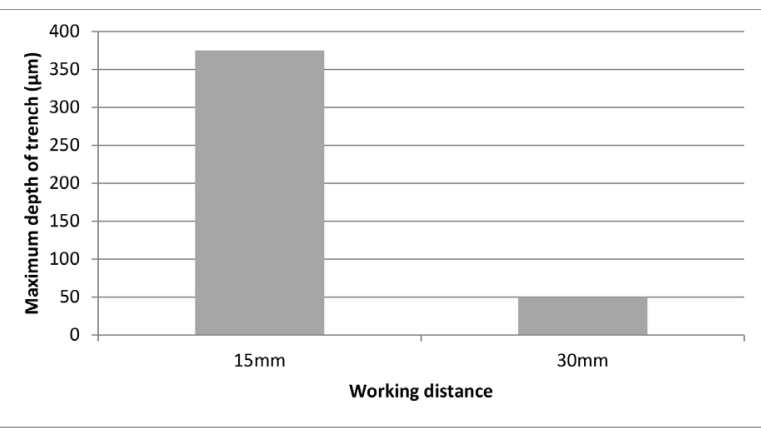

FIGURE 10. Comparison between working distances between the nozzle and the substrate using $50 \mu \mathrm{m}$ aluminium oxide powder.

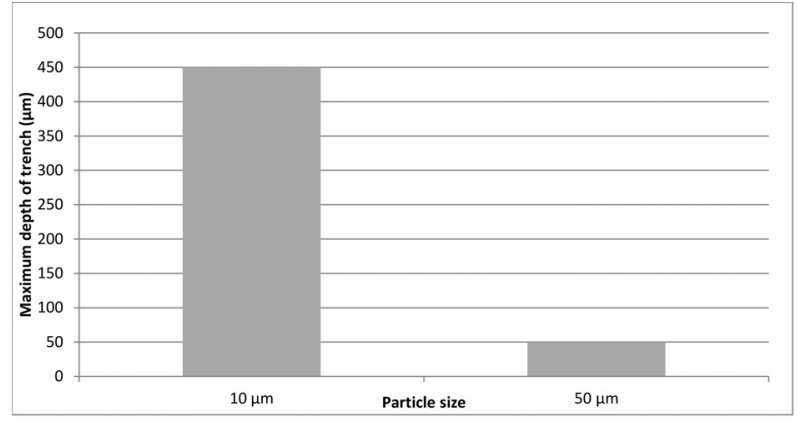

FIGURE 11. Comparison between powder size using aluminium oxide $30^{\circ}$ angle and $30 \mathrm{~mm}$ working distance between nozzle and substrate.

The increase in trench depth as the angle between the nozzle and substrate increases towards perpendicular would not necessarily be echoed by other substrates. The Solnhofen limestone seems to respond more to brittle failure than ductile failure. Particle shape (between crushed and bead glass, and between sodium bicarbonate and plastic) had very little effect on trench depth for the limestone used for this trial.

It must be noted that these tests were undertaken on only one type of matrix and other sedimentary rocks may react in different ways.

\section{HEALTH AND SAFETY CONSIDERATIONS}

The survey responses highlighted the need to improve awareness of the potential hazards associated with air-abrasive work. The main areas of risk are inhalation of dust particles, exposure to compressed air and high velocity abrasive powder. Here we consider some practical steps to mitigate such risks to the fossil preparator.

Care should be taken to ensure that the vulnerable parts of the body (hands, eyes, nose, mouth and ears) are adequately protected during air-abrasive work. Gauntlets or gloves, a facemask 


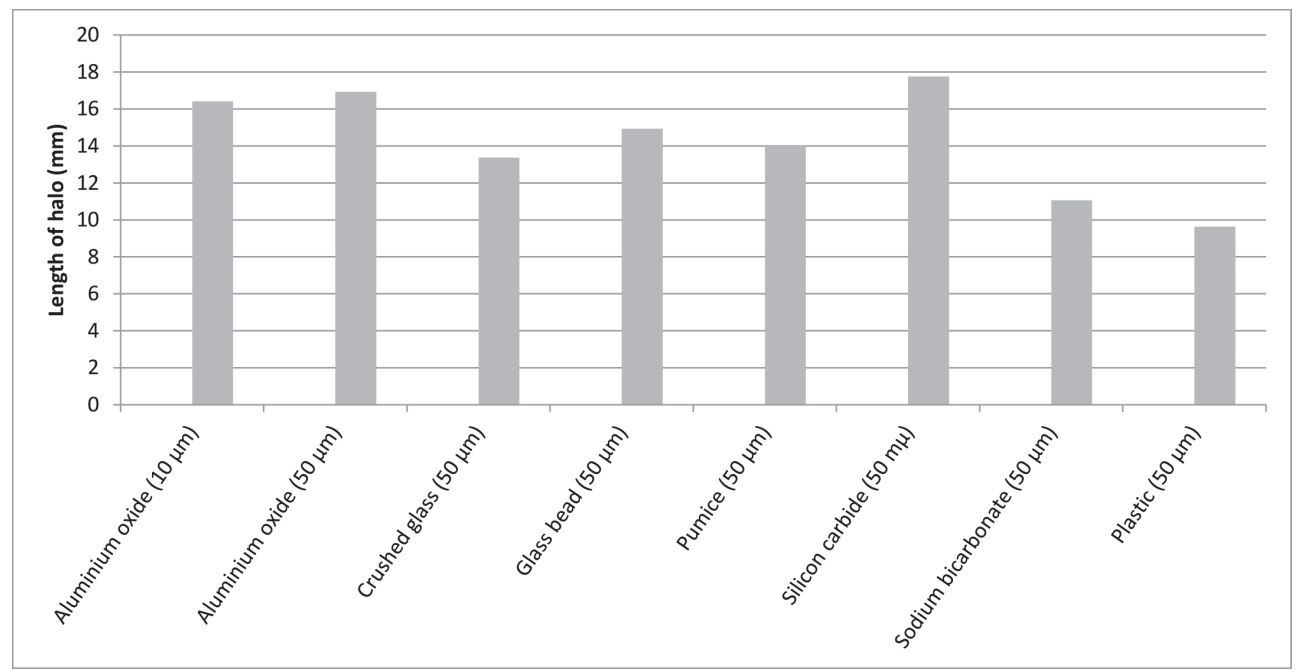

FIGURE 12. Comparison between trench scatter halo lengths of the various powders trialled with $30^{\circ}$ angle and 30 $\mathrm{mm}$ working distance between nozzle and substrate.

and earplugs or ear muffs should always be worn. Never should compressed air and abrasive powder be used around bare hands, as there is a risk of friction burns or, in serious cases (where compressed air enters a puncture), embolism. Protective glasses or goggles should always be worn to avoid particles scratching the surface of the eyes. A suitable (particulate proof) mask should be worn across the nose and mouth to avoid particle inhalation or ingestion (UK Health and Safety Executive, 2016). Crushed glass powder carries a potential risk of silicosis if inhaled, and walnut shell is potentially fatal to those with severe nut product allergies (http://www.bbc.co.uk/news/world-us-canada41726498), and therefore should be used only with extreme caution.

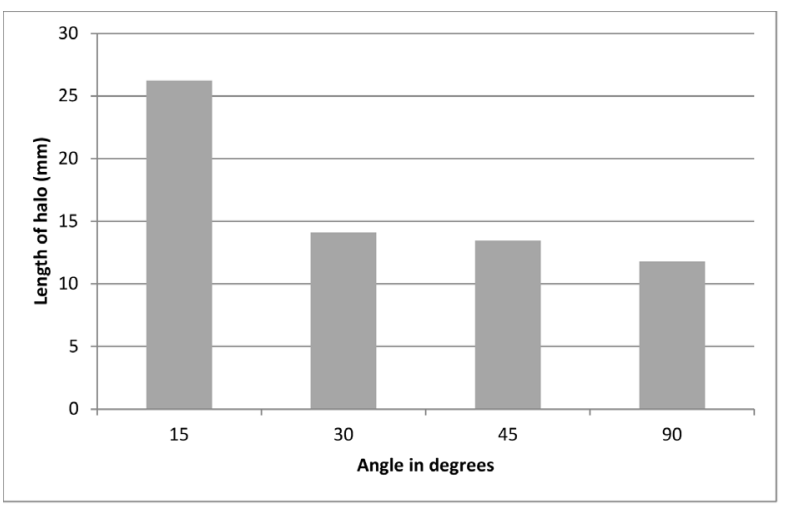

FIGURE 13. Comparison between trench scatter halos with varying angles using $50 \mu \mathrm{m}$ aluminium oxide powder.
The type of system used to extract and collect abrasive powder during the course of air-abrasive operation generally takes the form of ducting connected to a fan-operated extractor, with a filter bag or medium attached to collect the powder. In a laboratory environment the extraction unit may also be fitted with a 'shaker' function, so that powder is agitated off of the filter and into a collection tray. For the amateur or enthusiast, the set up may be be adapted from a household vacuum attached to the air blasting cabinet. Such equipment may be termed as a Local Exhaust Ventilation (LEV) system, and companies which use these as part of their operations to remove airborne hazardous substances from within a working environment must comply with the appropriate Health and safety legislation. Amateurs and enthusiasts may wish to consider how such guidelines may be adapted to their own activities to help protect themselves and remember to take precautionary measures when disposing of spent powder as well as during use.

LEV testing forms part of the H\&S enforcement process and ensures that companies comply with current health and safety legislation and Control of Substances Hazardous to Health (COSHH) regulations, so that potential health hazards are avoided and extraction systems are maintained in good working order. In the UK, The Health and Safety at Work Act 1974 and regulation 9 of the Control of Substances Hazardous to Health state that an LEV must be monitored and maintained to ensure it is in good working order including those that remove airborne dust and fumes (UK Health 
and Safety Executive, 2011). The test incorporates a complete inspection and examination of the LEV equipment and will also look at the working practices involved in its use. There is a statutory requirement for systems to be tested at least once every 14 months and, in certain situations more frequently.

\section{DESCRIPTION OF AIR-ABRASIVE TECHNIQUE}

Hannibal (1989) illustrated and described a typical air-abrasive set-up, which closely resembles that used today at the NHM London. Generally carried out within a blast cabinet (or behind clear shielding if it is impractical to contain the fossil), airabrasion should always be undertaken with adequate dust extraction running to remove spent powder and abraded matrix. Depending upon the system used, dust extraction is powered by a fan or vacuum, and the removed powder is contained within a filter medium or collection tank, which should be regularly emptied to maintain efficiency. The strength of ventilation required to remove particles effectively depends upon the volume of the blast cabinet. The abrasive powder should be sieved (with protective mask and eyewear worn) and completely dry before use and contained within a sealed, pressurised tank connected by tubing at the input to an air compressor and with the output (channelling the air/powder mix) tubing located inside the cabinet or behind the shielding. The decompression tube should be affixed inside the cabinet. The powder chamber should not be over-filled as this will inhibit free movement of the powder and may result in clogged tubing. A moisture trap fitted to both the compressed air feed and the compressor itself will further prevent dampening of the powder. Where the compressor motor has an oil reservoir, an in-line oil filter should also be fitted. A choice of nozzle (which can vary in aperture diameter and shape) is connected to the output tubing, usually via a threaded length of metal tubing to enable control over powder delivery.

For best results the interior of the blast cabinet should be illuminated with tube lighting and have a safety glass or clear Perspex ${ }^{\circledR}$ hinged lid to enable ease of access. The edges of the lid, where it rests on the (preferably recessed) cabinet sides, should have a seal strip added to form a powder-proof fit. Ideally a magnifying lens or microscope should be incorporated to allow for close, detailed work. The operator's hands access the cabinet via apertures, which should be secured against dust escape by a rubber or similar collar fitted around their circumference to form a barrier. The apertures may be fitted with permanent protective gauntlets or the operator may wear protective gloves. Air-abrasion while bare-handed represents a potential and easily avoidable risk to the preparator. It is also advisable and good practice, to wear a face mask and protective goggles to further protect against powder and dust, which may escape the cabinet and otherwise be ingested or cause irritation. Consideration should be given to the height and position of the cabinet, ensuring that operation can be carried out comfortably and with maximum visibility. As delivery of powder is best controlled via a foot pedal, the individual's optimal seat height should be taken into account.

Some fossils will need to be placed upon a sand bag or foam base within the cabinet while others may be held in a gloved hand during preparation. Careful consideration should be given to the appropriate type and particle size of abrasive powder most appropriate to the individual specimen to be prepared.

Air-abrasive units allow for air pressure (psi/ bar) and powder mix to be adjusted, and some feature a continuous or manual feed option. Regardless of feed option selected, the best way to proceed is with both pressure and mix set low, increasing either or both until a favourable balance is found (which will vary according to the properties of the material being worked). The manual feed option undoubtedly provides greater control, as the powder can be delivered in short blasts on a targeted area. Two key considerations are the distance between the nozzle and specimen and the angle of delivery of the powder stream. The closer the nozzle is to the specimen and more acute its angle, the greater the potential for damage. The best technique is therefore to angle the delivery of powder rather than pointing the nozzle straight-on and delivering the lowest practical powder/air mix in controlled bursts via the foot pedal. A steady, straight or circular movement of the nozzle, rather than a static delivery also reduces potential damage through excess concentration onto one area. Ensure that the cabinet is closed before turning off the air-abrasive unit, as it will decompress with a blast of air, which may agitate loose powder into a cloud, which should be allowed to settle. Do not switch on the air-abrasive if the lid of the powder canister is not secured, otherwise a flume of powder will escape into the working space. 


\section{CONCLUSIONS AND GENERAL RECOMMENDATIONS}

Air-abrasion is an extremely useful technique for fossil preparation, due to the control afforded by variability in powder type, airflow, air pressure, operating distance and angle. It is an ideal choice when chemical and percussive treatments are unsuitable, but preparators must always be aware of the risks from ricochet, even if protective barriers (such as cardboard or Paraloid ${ }^{\mathrm{TM}}$ B72) are employed and should never be used on friable fossils.

Fossil and rock preservation is extremely varied, and it is very difficult to recommend specific air-abrasive powders. Particle size, hardness and shape can, however, provide a starting point for the selection of the most appropriate material.

It is general best practice to start working at a lower pressure and particle hardness than anticipated and work up to a suitable combination. Unfortunately this can be impractical, unless the preparator has several machines, each filled with a different powder. At the Natural History Museum (NHM) London, UK, three machines are set up with the most commonly used powders: sodium bicarbonate and aluminium oxide, plus a machine for interchanging less prevalent powders. In some cases a preparator should switch powders, pressure and technique when bulk matrix has been removed and they begin to cut down to the fossil itself, and then again when cleaning films from the fossil surface is required.

Trench scatter experiments demonstrated the large distance that particles can travel away from the site of focus. We recommend that coarse powders used for bulk matrix removal are switched to the softer powder, to be used for specimen surface cleaning, at a distance of $15 \mathrm{~mm}$ from the specimen if aiming straight downwards, and progressively further away for angled approaches until 30 $\mathrm{mm}$ is reached for an angle of $15^{\circ}$.
As with all interventive processes undertaken on fossils or other materials and artifacts, the chemicals and techniques used must be discussed with stakeholders (such as curators and researchers) and procedures fully documented. Documentation is not only an ethical practice, but also provides a reference to aid decision-making in the future, whether a technique was effective, or whether it should in fact be avoided.

\section{Further Work}

This paper details the experimental results from tests restricted to one matrix and fossil type and only a selection of the powders available for air-abrasion. The revised technique, however, could be adapted to investigate any combination of variables (e.g., nozzle shapes, aperture diameter, blast angles, compressed air and powder mix settings, powder combinations) and their effect on different matrices and fossil surfaces.

\section{ACKNOWLEDGEMENTS}

The authors thank NHM UK colleagues L. Cornish (Head of Conservation) for helpful comments on an early draft of the manuscript and $\mathrm{T}$. Wighton (Mineral Preparator, Core Research Laboratories), for cutting the test matrix used in the experiments. M. Eklund, Research Associate, Vertebrate Paleontology Laboratory, Jackson School of Geosciences, Austin, Texas, is thanked for his helpful observations, and the anonymous referees at peer review stage are also thanked for their suggestions. All SEM images were undertaken by one of the authors (LAJ) with kind assistance from T. Goral and A. Ball of the Imaging and Analysis Centre (NHM). Finally we thank all of the international respondents to the online questionnaire, who provided such valuable insights.

\section{REFERENCES}

Airbrasive@. 2015. Powder selection guide. Accessed 1 October 2016. http:// www.airbrasive.com/wp-content/uploads/PowderSelectionGuideFinal.pdf

Airbrasive @. 2017a. Powders uses for microblasting. Accessed 12 July 2017. http:// www.airbrasive.com/faq/uses-for-micro-blasting/

Airbrasive C. 2017b. Learn how to control the micro blasting process. Accessed 12 July 2017. http://www.airbrasive.com/technical-support/controlling-the-process/ 
Allington-Jones, L. and Bernucci, A. 2015. Scanning electron microscope hypsometry as a tool for evaluating the impact of surface treatments: A case study on sub-fossil bone. Studies in Conservation, 60(1):55-64. http://dx.doi.org/10.1179/2047058413Y.0000000123

Allman, M. and Lawrence, D.F. 1972. Geological Laboratory Techniques. Blandford, London.

Bernard, H.M. 1894. On the application of the sand-blast for the development of trilobites. Geological Magazine, 1(12):553-557. https://doi.org/10.1017/s0016756800145315

Blackshaw, S. M. 1982. An appraisal of cleaning methods for use on corroded iron antiquities. In Clarke, R.W. and Blackshaw, S.M. (eds.) Conservation of Iron. Maritime monographs and reports. 53. National Maritime Museum, London. 73.

Considine, B.B. 2010. Conserving Outdoor Sculpture: the Stark Collection at the Getty Centre. The Getty Conservation Institute: Los Angeles.

Converse, H.H. 1984. Handbook of Paleo-Preparation Techniques (2nd ed), Florida Paleontological Society. Florida Museum of Natural History, Gainesville, Florida.

Dickman, K., Hildenhagen, J., Studer, S., and Müsch, E. 2005. Archaeological ironwork: removal of corrosion layers by Nd:YAG-Laser, p.71-77. In Dickmann, K., Fotakis C., and Asmus J.F. (eds.), Lasers in the Conservation of Artworks. LACONA V Proceedings, Osnabrück, Germany, Sept. 15-18, 2003. Springer Proceedings in Physics 100. Springer: Berlin. https:// doi.org/10.1007/3-540-27176-7_9

Gibson, B.M. 1969. The use of the airbrasive process for cleaning ethnological materials. Studies in Conservation, 14(4):155-164. https://doi.org/10.2307/1505339

Green, O.R. 2001. A Manual of Practical Laboratory and Field Techniques in Palaeobiology. Kluwer Academic Publishers, London.

Gunther, L.F, Gunther, V.G., and Rigby, J.K. 1979. An economic miniature sandblaster for preparation of fossils. Journal of Paleontology, 53(2):506-507.

Hannibal, J.T., Williams, M.E,. and Jackson, G.L. 1988. An inexpensive source of dolomite powder for use with airbrasive units. Journal of Paleontology, 62(2):316.

Hannibal, J.T. 1989. The air-abrasive technique. p. 227-235. In Feldman, R.M., Chapman, R.E., and Hannibal J.T. (eds.), Paleotechniques, The Paleontological Society Special Publication No.4.

Koh, Y.S., Powell, J., Kaplan, A., and Carlevi, J. 2007. Laser cleaning of corroded steel surfaces: A comparison with mechanical cleaning methods, p. 13-20. In Nimmrichter, J., Kautek W., and Schreiner, M. (eds.), Lasers in the Conservation of Artworks, LACONA VI Proceedings, Vienna, Austria, Sept. 21-25, 2005. Springer Proceedings in Physics 116. Springer, Berlin. https://doi.org/10.1007/978-3-540-72310-7_2

Larson, J. 2011. The conservation of stone sculpture in museum, p.197-207. In Ashurst, J. and Dimes, F.G. (eds.), Conservation of Building and Decorative Stone, Routledge: London.

Larson, J. and Dinsmore, J. 1984. The treatment of polychrome medieval English stone sculpture in the museum environment, p.167-170. In Brommelle, N.S., Pye, E.M., Smith P., and Thomson, G. (eds.), Adhesives and Consolidants, Preprints of the Contributions to the Paris Congress, 2-8 September 1984. IIC, London. https://doi.org/10.1179/ sic.1984.29.Supplement-1.167

May, P., Reser, P., and Leiggi, P. 1994. Macrovertebrate preparation. p.113-129. In Leiggi, P and May, P. (eds.), Vertebrate Paleontological Techniques, Volume 1. Cambridge University Press, Cambridge.

Osborn, H.F. 1904. On the use of sandblast in cleaning fossils. Science, 19:256.

Rixon, A.E. 1976. Fossil Animal Remains: Their Preparation and Conservation. Athlone Press, London.

Spreng, A.C. 1962. Airbrasive cleaning tool. Journal of Paleontology, 36(6):1391-1392.

Stucker, G.F. 1961. Salvaging fossils by jet. Curator, 4(4):332-340.

Stucker, G.F., Galusha, M.J., and McKenna, M.C. 1965. Removing matrix from fossils by miniature sandblasting, p. 273-274. In Kummel, B. and Raup, D. (eds.), Handbook of Palaeontological Techniques. W.H. Freeman and Company, London.

Swan, J. 2011. Cleaning with micro sandblasters, p. 381-395. In Kanegsberg, B. and Kanegsberg, E. (eds.), Handbook for Critical Cleaning. Taylor and Francis, London.

UK Health and Safety Executive. 2011. Controlling airborne contaminants at work - a guide to local exhaust ventilation (LEV) Accessed 8th August 2017. http://www.hse.gov.uk/pUbns/ priced/hsg258.pdf

UK Health and Safety Executive. 2016. Abrasive Blasting. Accessed 8th August 2017. http:// www.hse.gov.uk/pubns/guidance/cn7.pdf 
Veloz, N. F. and Chase, W. T. 1989. Airbrasive cleaning of statuary and other structures: a century of technical examination of blasting procedures. Technology \& Conservation, 10(1):18-38.

Wilson, J. 1995. Conservation and processing - cleaning and mechanical preparation, p.89-94. In Collins, C. (ed.), The Care and Conservation of Palaeontological Material. ButterworthHeinemann, Oxford. 


\section{APPENDIX 1.}

Complete results from online survey (available online at palaeo-electronica.org/content/2018/ 2279-air-abrasive-fossil-preparation). 